\title{
Analysis of the pattern of potential woody cover in Texas savanna
}

\author{
Xuebin Yang ${ }^{1, *}$, Kelley A. Crews ${ }^{1}$, Bowei Yan ${ }^{2}$ \\ 1. Department of Geography and the Environment, The University of Texas at Austin, Austin, TX78731, \\ USA \\ 2. Department of Statistics and Data Science, The University of Texas at Austin, Austin, TX78731, USA
}

\begin{abstract}
While woody plant encroachment has been observed worldwide in savannas and adversely affected the ecosystem structure and function, a thorough understanding of the nature of this phenomenon is urgently required for savanna management and restoration. Among others, potential woody cover (the maximum realizable woody cover that a given site can support), especially its variation over environment has huge implication on the encroachment management in particular, and on tree-grass interactions in general. This project was designed to explore the pattern of potential woody cover in Texas savanna, an ecosystem with a large rainfall gradient in west-east direction. Substantial random pixels were sampled across the study area from MODIS Vegetation Continuous Fields (VCF) tree cover layer $(250 \mathrm{~m})$. Since potential woody cover is suggested to be limited by water availability, a nonlinear $99^{\text {th }}$ quantile regression was performed between the observed woody cover and mean annual precipitation (MAP) to model the pattern of potential woody cover. Research result suggests a segmented relationship between potential woody cover and MAP at MODIS scale. Potential biases as well as the practical and theoretical implications were discussed. Through this study, the hypothesis about the primary role of water availability in determining savanna woody cover was further confirmed in a relatively understudied US-located savanna.
\end{abstract}

Key words: Texas savanna, potential woody cover, woody plant encroachment, nonlinear quantile regression, MODIS VCF

\section{Introduction}

Savanna ecosystems are characterized by the coexistence of woody and herbaceous vegetation (Frost et al., 1986). They exist across a wide range of conditions in terms of climate (e.g. rainfall), soil nutrient content, fire regimes and herbivory level, covering about $20 \%$ of the Earth's terrestrial surface (Ramankutty \& Foley, 1999). Mainly found in tropics and subtropics, savannas are home to a large proportion of human population, livestock and wildlife of the world. Moreover, savanna ecosystems play a critical role in global land-atmosphere energy balance, as well as carbon, nutrient, and water cycles (Scholes \& Walker, 1993; Lal, 2004).

Many theories have been advanced to explain the coexistence and relative abundance of woody and herbaceous components in savannas, which can be categorized into two broad classes (Walter, 1971; van Langevelde et al., 2003; Higgins et al., 2000). While one is based upon the competitive interactions between the two contrasting life forms, the other focuses exclusively on tree establishment and persistence restricted by demographic bottlenecks (Sankaran et al., 2004). However, both positive and negative evidence exists for each category of those theories, and none of them is generalizable across all types of savannas (Scholes \& Archer, 1997; Jeltsch et al., 2000). Other than that, savanna dynamics have been debated with regard to equilibrium, nonequilibrium, and disequilibrium dynamics (Ellis \& Swift, 1988; Sullivan \& Rohde, 2002). As for 
savanna modeling community, the validity of traditional succession models versus state-andtransition models needs further investigation (Fowler \& Simmons, 2008).

Furthermore, the phenomenon of woody plant encroachment, defined as the directional increase of woody plants at the expense of herbaceous vegetation, commends the relevance of illuminating the above 'savanna questions'. This is because that the encroachment has been observed in southern United States (Archer et al., 1995; Creamer et al., 2013) and many other parts of the world (Cabral et al., 2003; Soliveres \& Eldridge, 2014; Coetsee et al., 2013). And it has adversely affected the ecosystem production and function, and largely reduced species diversity (Hughes et al., 2006; Van Auken, 2009; Alofs \& Fowler, 2010). A thorough understanding of the aforementioned alternative mechanisms and dynamics is urgently required for woody encroachment management, especially in consideration of changing climate and land use patterns anticipated to worsen the scenario (Sala et al., 2000; House et al., 2003; IPCC, 2014). Potential woody cover - the maximum realizable woody cover that a given site can support - would provide insights into these 'savanna questions'.

\section{Background}

During the past several decades, substantial increase in woody plants has been observed on the Edwards Plateau of Texas, USA (Archer, 1989; Taylor, 2008; Alofs \& Fowler, 2010). The encroachment was attributed to the expansion of existing woody species and establishment of new woody species, accompanied by a significant amount of temporal and spatial heterogeneity in fire regimes and herbivory level (González, 2010; Alofs \& Fowler, 2013). Being unfavorable to the dominant herbivores in this region (domestic livestock and deer), the encroaching species of Ashe juniper and red berry juniper now dominate much of the plateau, largely reducing livestock production and regional plant diversity (Fowler \& Simmons, 2008; Creamer et al., 2013).

Facing the huge encroachment, both conservation managers and research ecologists are concerned about the potential woody cover (the hypothetical degree of encroachment), as well as the alternative of succession models and state-and-transition models for savanna dynamics modeling. If potential woody cover is well below canopy closure, woody plant encroachment will be a bounded process (Sankaran et al., 2005). Otherwise, savannas may switch to a wooded state as a result of the encroachment, and disturbances such as fire and herbivory will be necessary for the persistence of woody and herbaceous vegetation. While succession models emphasize an ordered series of states during the development of savannas (Fowler \& Simmons, 2008), the state-and-transition models consider reversible stable states (Briske et al., 2005; Bestelmeyer et al., 2009). If succession models fit Texas savanna dynamics, the encroachment will persist and the savanna will develop toward a more and more woody state. Otherwise, if the state-and-transition models fit better, the encroachment will be a reversible process with or without human manipulation and it will be a much easier task to combat with the encroachment.

It is hypothesized that the potential woody cover that a given site can support is predominantly limited by water availability (Frost et al., 1986; Sankaran et al., 2008). Research also suggests that, if water availability plays the primary role in determining woody cover in savannas, the potential woody cover would show a gradual increasing trend with mean annual precipitation (MAP) (Walker \& Noy-Meir, 1982; Sankaran et al., 2004, 2005). But if factors such as fire and herbivory play the primary roles, an abrupt increase in potential woody cover would be observed 
over rainfall gradient. That is, a dominance of grassland will be found in areas below a MAP threshold, while woody canopy closure would occur in areas above that threshold sufficient for woody plant growth (Frost et al., 1986; Jeltsch et al., 2000).

Sankaran et al. (2005) analyzed the potential woody cover in African savannas applying the above MAP-based scheme. However, analogous research in other savanna regions has been rarely seen. And the pattern of the potential woody cover of other savanna ecosystems remains to be established, which could be different from that of the African savannas due to the relatively unexplored factors such as soil characteristic and climate seasonality (Kulmatiski \& Beard, 2013). Given so, this study was designed to investigate the potential woody cover across broad environmental gradients in Texas savanna. While field sites were restricted to a fine scale of 0.25 to 0.5 ha in the African research, a coarse scale study would enrich the theory of scaledependency of woody cover observation (Gillson, 2004; Wiegand et al., 2006).

\section{Methods}

\subsection{Study area}

This study was tested on the Edwards Plateau of Texas, USA (Fig. 1). The plateau is a unique ecoregion of Texas, characterized by juniper-oak savanna and mesquite-Acacia savanna with middle to short herbaceous vegetation (Küchler, 1964; Fowler \& Simmons, 2008). It is adjacent with dry plains on its western border, and moist prairies and woods to the east. The plateau is roughly an oblong region in which a large rainfall gradient is present, with mean annual precipitation ranging from $\sim 360 \mathrm{~mm}$ to $\sim 950 \mathrm{~mm}$ in the west-east direction. It has thick and mostly flat bedrock, mainly consisting of hard early Cretaceous limestone. Due the origin of limestone, soil in this region is generally shallow (less than 10 inches) and rich in clay content (Schmid, 1969). The study area is displayed with Landsat GeoCover Mosaics of 2000, under band combination of 7, 4 and 2 for a natural-like rendition (Fig. 1).

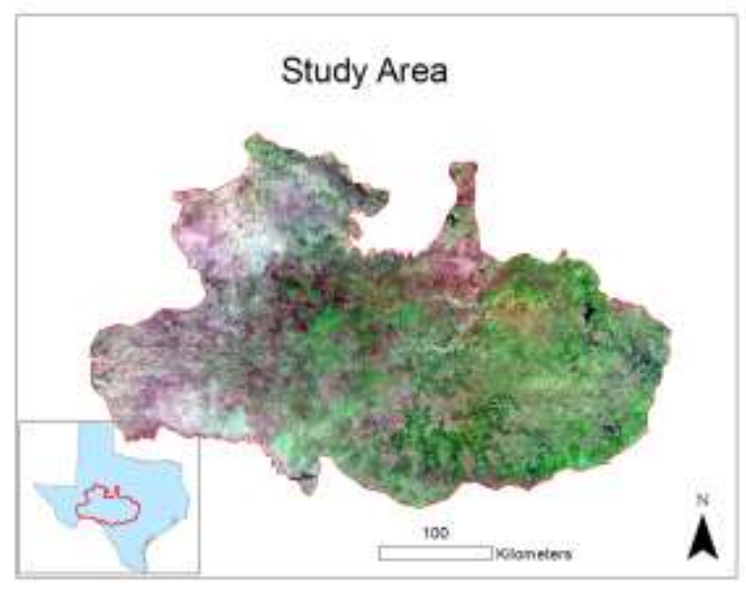

Figure 1. The study area in Texas, USA.

\subsection{Data acquisition}

MODIS Vegetation Continuous Fields (VCF) is an annual product that estimates the proportion of tree cover, non-tree vegetation and bare ground of global land surface at MODIS pixel level 
(DiMiceli et al., 2011). The VCF product has been widely used in a variety of research and application (Bucini \& Hanan, 2007; Song et al., 2014). As the only large scale and proportional tree cover dataset available, the MODIS VCF tree cover layer is able to provide us a very large sample to examine the pattern of potential woody cover over broad environmental gradients that is difficult to discern by a small number of observations. The latest MODIS VCF tree cover of 2013 (250m resolution) was utilized in this research.

Precipitation data was acquired from Southern Regional Climate Center. MAP from 1981 to 2010 was calculated in millimeters for 51 rain gauge stations within this study area. Thereafter, a continuous MAP surface was created at $250 \mathrm{~m}$ resolution. The interpolation method of Kriging was applied, which proves more realistic compared to other methods (Ly et al., 2013). The MAP surface and MODIS tree cover layer are displayed in figure 2.
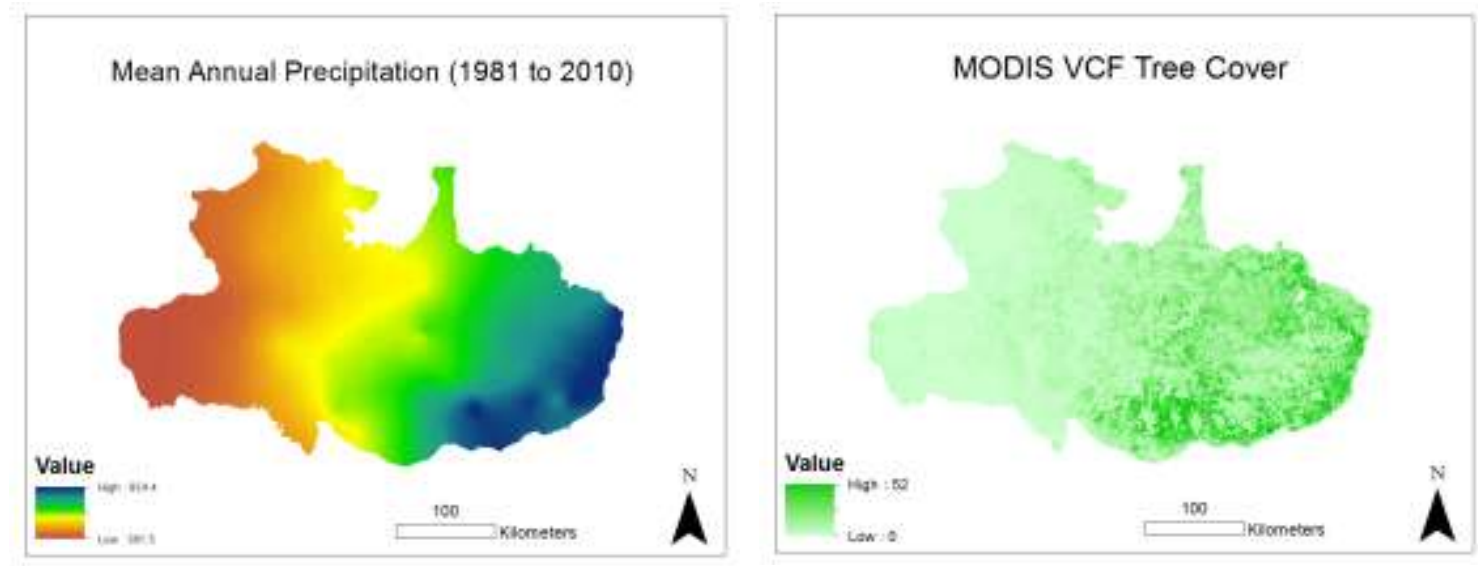

Figure 2. Mean annual precipitation and MODIS VCF tree cover of the study area.

\subsection{Data sampling}

Spatial random sampling was performed across the study area with the MODIS VCF tree cover layer in ArcGIS 10.3, creating a total of 10,000 random pixels. Corresponding proportional tree cover and MAP values were extracted for the sample. Pixels with tree cover values greater than $100 \%$ (due to water, cloud, shadow, or filled value) were excluded. The scatterplot of MODIS proportional tree cover vs. MAP is exhibited in figure 3.

\subsection{Data analysis}

\subsubsection{Quantile regression}

Regression analysis has long been used in ecology study for investigation of relationships between ecological processes and associated factors (Cade \& Noon, 2003). While traditional regression analysis focuses on the mean of the response variable distribution, quantile regression is capable of estimating the relationship between measured factors and all parts of the response variable distribution (Koenker \& Bassett, 1978). Thus, quantile regression is able to provide a more complete insight into the possible causes of ecological processes (Koenker et al., 1994; Cade \& Guo, 2000; Dunham et al., 2002; Brown \& Peet, 2003). 
Specifically, many ecologists choose to fit the upper boundary of the conditional distribution of ecological responses to the factors of interest (Cade \& Guo, 2000). It is due to that, though only a portion of the associated factors are measured and included in most ecology studies, the upper limit set by the measured factors cannot be exceeded even when other potential factors are included (Cade \& Noon, 2003). Though a parametric form of the relationship is assumed for quantile regression, no hypothesis is made about the distributional form (e.g. normal, Poisson) of the random error portion of the analysis.

\subsubsection{Data analysis}

Within figure 3, an overall increasing trend of woody cover with MAP is evident. To explore the pattern of potential woody cover, a nonlinear quantile regression was performed between the observed woody cover and MAP, with the package 'quantreg' in software R. The potential woody cover was represented by the $99^{\text {th }}$ quantile of the observed woody cover (Sankaran et al., 2005). While various functions were tested, the exponential function $y=a+c * \exp (-\exp (-b *(x-m)))$ fits the scatterplot best, confirmed by an additional linear b-spline quantile regression. The fitted curve is displayed in red in figure 3.

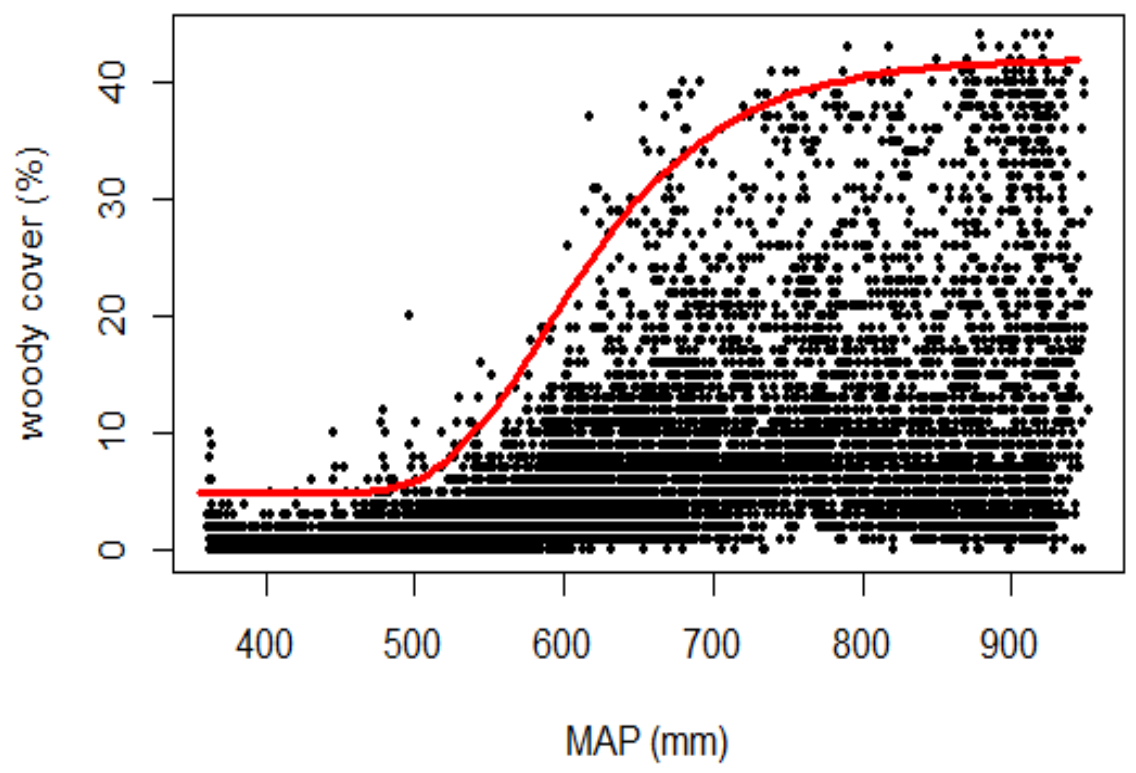

Figure 3. Scatterplot of MODIS tree cover vs. MAP and the pattern of potential woody cover (red line).

\section{Result and Discussion}

\subsection{Result}

As shown in figure 3, the curve of the potential woody cover at MODIS scale is in a sigmoid shape, suggesting a segmented relationship between potential woody cover and MAP in Texas savanna. The potential woody cover starts with a fixed and very low level till $500 \mathrm{~mm}$ MAP, 
followed by an approximate linear relationship with MAP by about $650 \mathrm{~mm}$. From $650 \mathrm{~mm}$ on, the potential woody cover stays on a plateau value of about $42 \%$.

It has to be noted that the MODIS VCF tree cover product does not include woody plants less than 5 meters height in their calibration data, while a lot of short woody plants exist in Texas savanna (DiMiceli et al., 2011; Sexton et al., 2013). Though it does not mean that the small woody plants don't appear in the imagery with similar spectral implications, underestimation may occur with the tree cover product within this study area. It coincided with our visual estimation from Google Earth high resolution imagery, which indicates a higher upper bound than that of $42 \%$. Even though further research is needed on the upper bound value, the segmented relationship between potential woody cover and mean annual precipitation can provide us a lot of insights into woody encroachment management and the mechanisms of treegrass interactions in Texas savanna.

\subsection{Discussion}

This study follows the research by Sankaran et al. (2005) that suggests a similar potential woody cover pattern but a much higher upper bound in African savannas (about 80\%). Besides the potential underestimation of the MODIS tree cover product, the discrepancy may be attributed to several other aspects. First of all, compared to the fine scale ( 0.25 to $.05 \mathrm{ha}$ ) in the African study, the MODIS scale (6.25 ha) is much less sensitive to local heterogeneity and thus less likely to capture high woody cover of local dense locations.

Secondly, different soil characteristics would take part of the responsibility (Bucini \& Hanan, 2007). Developed from limestone, soil in Texas savanna is shallow and coarse-textured (Schmid, 1969). It is suggested by the inverse texture hypothesis that coarse-textured soil supports less woody plants in wetter climates than fine-textured soil (Noy-Meir, 1973). With this in mind, the soil in African savannas is mushy in its long wet season. On the other hand, the soil in the dry season of African savannas is very porous and dry. This type of soil facilitates natural fires that fertilize the soil through the reintegration of ash, and consequently sustains plant growth.

Lastly, climate seasonality such as temperature, timing and intensity of precipitation can also affect potential woody cover through their effect on water partitioning between woody and herbaceous plants (Kulmatiski \& Beard, 2013). For example, rainfall mainly occurs in May/June and September in Texas savanna, while the wet season stretches from May to November in African savannas (Mistry \& Beradi, 2014). It is possible that the longer wet season in African savannas facilitates woody plant growth.

The gradual increasing trend of potential woody plant cover with MAP further confirmed the hypothesis of the primary determinant role of water availability in savanna woody cover in a northern hemisphere savanna. In the relatively dry areas (with MAP below the threshold value of $650 \mathrm{~mm}$ ), potential woody cover is limited by water availability. Increased water availability in these areas will increase their potential in supporting tree growth and facilitating woody plant encroachment. Therefore, any changes that lead to increased water availability for woody plants such as changes in precipitation regimes and soil properties should be a concern for woody encroachment management.

In savanna dynamics, the distinction between independent (constraints or disturbances) and dependent (interactive) environmental factors depends on observation scale (Skarpe, 1992). 
Moreover, the distinction is also environment-specific. According to this study, woody plant growth in the relatively dry areas in Texas savanna is constrained by water availability, suggesting that MAP acts as an independent factor in savanna dynamics. In mesic areas with MAP above $650 \mathrm{~mm}$, rainfall is sufficient for woody plant growth and is more likely a part of the interactive mechanisms of the savanna dynamics. It also indicates that a combination of competition-based theories and demographic-bottleneck theories is necessary for a full understanding of the savanna dynamics.

Research shows how the increasing woody plants in Texas savanna will persist under present conditions without mechanical removing (Fowler \& Simmons, 2008). The successional process of woody plant encroachment in Texas savanna indicates that traditional succession models characterized by transient dynamics may better depict its present dynamics, compared to the widely used state-and-transition models with reversible alternate stable states. Since the successional process continues until a climax point is reached, the process of woody plant encroachment will not stop until its potential woody cover is realized.

\section{Conclusions}

The result of this study unveils the pattern of potential woody cover over broad environmental gradients in Texas savanna, further confirming the hypothesis of the primary role of water availability in determining savanna woody cover in a relatively understudied US-located savanna. In addition, this project's findings highlight the role of factors other than MAP such as soil characteristic and climate seasonality in affecting potential woody cover. Due to the scale dependency of woody cover observation, future studies at finer scales would provide a more complete picture of the pattern of potential woody cover in Texas savanna.

Above all, this study further unveils the fundamental nature of savannas and serves as a baseline for further work concerning savanna management and restoration. It is important to note that the usage of MODIS VCF tree cover product was critical. Despite of the aforementioned potential bias, this dataset in particular, as well as satellite-based regional-scale earth observation techniques in general, exhibit great potential in uncovering the nature of global environmental systems.

\section{Acknowledgements}

This material is based upon work supported by the National Science Foundation under Grant No. 0964596. The Digital Landscapes Lab (http://www.digitallandscapes.org) and associated Spatial Sciences Lab in the Department of Geography \& the Environment at the University of Texas at Austin also provided advice and support. We gratefully acknowledge the critical comments of the two anonymous reviewers. Many thanks to Ms. Jennifer Zuehlke and Ms. Emily E. Mixon for their assistance in technical editing. 


\section{References}

Alofs, K. M., and N. L. Fowler. 2010. Habitat fragmentation caused by woody plant encroachment inhibits the spread of an invasive grass. Journal of Applied Ecology 47 (2):338-347.

Alofs, K. M., and N. L. Fowler. 2013. Loss of native herbaceous species due to woody plant encroachment facilitates the establishment of an invasive grass. Ecology 94 (3):751-760.

Archer, S. 1989. Have southern Texas savannas been converted to woodlands in recent history? American naturalist:545-561.

Archer, S., D. S. Schimel, and E. A. Holland. 1995. Mechanisms of shrubland expansion: land use, climate or CO2? Climatic Change 29 (1):91-99.

Bestelmeyer, B. T., A. J. Tugel, G. L. Peacock, D. G. Robinett, P. L. Shaver, J. R. Brown, J. E. Herrick, H. Sanchez, and K. M. Havstad. 2009. State-and-transition models for heterogeneous landscapes: a strategy for development and application. Rangeland Ecology \& Management 62 (1):1-15.

Briske, D. D., S. D. Fuhlendorf, and F. E. Smeins. 2005. State-and-transition models, thresholds, and rangeland health: a synthesis of ecological concepts and perspectives. Rangeland Ecology \& Management $58(1): 1-10$.

Brown, R. L., and R. K. Peet. 2003. Diversity and invasibility of southern Appalachian plant communities. Ecology 84 (1):32-39.

Bucini, G., and N. P. Hanan. 2007. A continental-scale analysis of tree cover in African savannas. Global Ecology and Biogeography 16 (5):593-605.

Cabral, A. C., J. M. Miguel, A. J. Rescia, M. F. Schmitz, and F. D. Pineda. 2003. Shrub encroachment in Argentinean savannas. Journal of Vegetation Science 14 (2):145-152.

Cade, B. S., and B. R. Noon. 2003. A gentle introduction to quantile regression for ecologists. Frontiers in Ecology and the Environment 1 (8):412-420.

Cade, B. S., and Q. Guo. 2000. Estimating effects of constraints on plant performance with regression quantiles. Oikos 91 (2):245-254.

Change, I. P. on C. 2014. Climate Change 2014-Impacts, Adaptation and Vulnerability: Regional Aspects. Cambridge University Press.

Coetsee, C., E. F. Gray, J. Wakeling, B. J. Wigley, and W. J. Bond. 2013. Low gains in ecosystem carbon with woody plant encroachment in a South African savanna. Journal of Tropical Ecology 29 (1):49-60.

Creamer, C. A., T. R. Filley, D. C. Olk, D. E. Stott, V. Dooling, and T. W. Boutton. 2013. Changes to soil organic $\mathrm{N}$ dynamics with leguminous woody plant encroachment into grasslands. Biogeochemistry 113 (1-3):307-321.

DiMiceli, C. M., M. L. Carroll, R. A. Sohlberg, C. Huang, M. C. Hansen, J. R. G. Townshend, and others. 2011. Annual global automated MODIS vegetation continuous fields (MOD44B) at $250 \mathrm{~m}$ spatial resolution for data years beginning day 65, 2000-2010, collection 5 percent tree cover. University of Maryland, College Park, MD, USA.

Dunham, J. B., B. S. Cade, and J. W. Terrell. 2002. Influences of spatial and temporal variation on fishhabitat relationships defined by regression quantiles. Transactions of the American Fisheries Society 131 (1):86-98.

Ellis, J. E., and D. M. Swift. 1988. Stability of African pastoral ecosystems: alternate paradigms and implications for development. Journal of Range Management Archives 41 (6):450-459. 
Fowler, N. L., and M. T. Simmons. 2008. Savanna dynamics in central Texas: just succession? Applied Vegetation Science 12 (1):23-31.

Frost, C. C., J. Walker, and R. K. Peet. 1986. Fire-dependent savannas and prairies of the Southeast: Original extent, preservation status and management problems. Wilderness and natural areas in the eastern United States: a management challenge. Nacogdoches, TX: Stephen F. Austin State University, School of Forestry, Center for Applied Studies:348-357.

Gillson, L. 2004. Testing non-equilibrium theories in savannas: 1400 years of vegetation change in Tsavo National Park, Kenya. Ecological Complexity 1 (4):281-298.

Higgins, S. I., W. J. Bond, and W. S. Trollope. 2000. Fire, resprouting and variability: a recipe for grasstree coexistence in savanna. Journal of Ecology 88 (2):213-229.

House, J. I., S. Archer, D. D. Breshears, and R. J. Scholes. 2003. Conundrums in mixed woodyherbaceous plant systems. Journal of biogeography 30 (11):1763-1777.

Hughes, R. F., S. R. Archer, G. P. Asner, C. A. Wessman, C. McMurtry, J. I. M. Nelson, and R. J. Ansley. 2006. Changes in aboveground primary production and carbon and nitrogen pools accompanying woody plant encroachment in a temperate savanna. Global Change Biology 12 (9):1733-1747.

Jeltsch, F., G. E. Weber, and V. Grimm. 2000. Ecological buffering mechanisms in savannas: a unifying theory of long-term tree-grass coexistence. Plant Ecology 150 (1-2):161-171.

Koenker, R., and G. Bassett Jr. 1978. Regression quantiles. Econometrica: journal of the Econometric Society:33-50.

Koenker, R., P. Ng, and S. Portnoy. 1994. Quantile smoothing splines. Biometrika 81 (4):673-680.

Küchler, A. W. 1964. Potential natural vegetation of the conterminous United States. American Geographical Society.

Kulmatiski, A., and K. H. Beard. 2013. Woody plant encroachment facilitated by increased precipitation intensity. Nature Climate Change 3 (9):833-837.

Lal, R. 2004. Carbon sequestration in dryland agriculture. Challenges and Strategies of Dryland Agriculture (challengesandst):315-334.

Ly, S., C. Charles, and A. Degré. 2013. Different methods for spatial interpolation of rainfall data for operational hydrology and hydrological modeling at watershed scale. A review. Biotechnologie, Agronomie, Société et Environnement 17 (2):392.

Mistry, J., and A. Beradi. 2014. World savannas: ecology and human use. Routledge.

Noy-Meir, I. 1973. Desert ecosystems: environment and producers. Annual review of ecology and systematics:25-51.

Ramankutty, N., and J. A. Foley. 1999. Estimating historical changes in global land cover: Croplands from 1700 to 1992. Global biogeochemical cycles 13 (4):997-1027.

Sala, O. E., F. S. Chapin, J. J. Armesto, E. Berlow, J. Bloomfield, R. Dirzo, E. Huber-Sanwald, L. F. Huenneke, R. B. Jackson, A. Kinzig, and others. 2000. Global biodiversity scenarios for the year 2100. science 287 (5459):1770-1774.

Sankaran, M., J. Ratnam, and N. Hanan. 2008. Woody cover in African savannas: the role of resources, fire and herbivory. Global Ecology and Biogeography 17 (2):236-245.

Sankaran, M., J. Ratnam, and N. P. Hanan. 2004. Tree-grass coexistence in savannas revisited-insights from an examination of assumptions and mechanisms invoked in existing models. Ecology Letters 7 (6):480-490. 
Sankaran, M., N. P. Hanan, R. J. Scholes, J. Ratnam, D. J. Augustine, B. S. Cade, J. Gignoux, S. I. Higgins, X. Le Roux, F. Ludwig, and others. 2005. Determinants of woody cover in African savannas. Nature 438 (7069):846-849.

Schmid, J. 1969. The Wild Landscape of the Edwards Plateau of Southcentral Texas: A Study of Developing Lifelihood Patterns and Ecological Change.

Scholes, R. J., and B. H. Walker. 1993. African savannas: an overview. An African savanna: synthesis of the Nylsvley study:2-16.

Scholes, R. J., and S. R. Archer. 1997. Tree-grass interactions in savannas. Annual review of Ecology and Systematics:517-544.

Sexton, J. O., X.-P. Song, M. Feng, P. Noojipady, A. Anand, C. Huang, D.-H. Kim, K. M. Collins, S. Channan, C. DiMiceli, and others. 2013. Global, 30-m resolution continuous fields of tree cover: Landsatbased rescaling of MODIS vegetation continuous fields with lidar-based estimates of error. International Journal of Digital Earth 6 (5):427-448.

Skarpe, C. 1992. Dynamics of savanna ecosystems. Journal of vegetation Science 3 (3):293-300.

Soliveres, S., and D. J. Eldridge. 2014. Do changes in grazing pressure and the degree of shrub encroachment alter the effects of individual shrubs on understorey plant communities and soil function? Functional ecology 28 (2):530-537.

Song, X.-P., C. Huang, M. Feng, J. O. Sexton, S. Channan, and J. R. Townshend. 2014. Integrating global land cover products for improved forest cover characterization: An application in North America. International Journal of Digital Earth 7 (9):709-724.

Sullivan, S., and R. Rohde. 2002. On non-equilibrium in arid and semi-arid grazing systems. Journal of Biogeography 29 (12):1595-1618.

Taylor Jr, C. A. 2008. Ecological consequences of using prescribed fire and herbivory to manage Juniperus encroachment. In Western North American Juniperus Communities, 239-252. Springer.

Van Auken, O. W. 2009. Causes and consequences of woody plant encroachment into western North American grasslands. Journal of Environmental Management 90 (10):2931-2942.

Van Langevelde, F., C. A. Van De Vijver, L. Kumar, J. Van De Koppel, N. De Ridder, J. Van Andel, A. K. Skidmore, J. W. Hearne, L. Stroosnijder, W. J. Bond, and others. 2003. Effects of fire and herbivory on the stability of savanna ecosystems. Ecology 84 (2):337-350.

Walker, B. H., and I. Noy-Meir. 1982. Aspects of the stability and resilience of savanna ecosystems. In Ecology of tropical savannas, 556-590. Springer.

Walter, H., J. H. Burnett, and D. Mueller-Dombois. 1971. Ecology of tropical and subtropical vegetation. Oliver and Boyd Edinburgh.

Wiegand, K., D. Saltz, and D. Ward. 2006. A patch-dynamics approach to savanna dynamics and woody plant encroachment-insights from an arid savanna. Perspectives in Plant Ecology, Evolution and Systematics 7 (4):229-242. 